\title{
EFFECTS OF TULSI, BLACK PEPPER AND CLOVES EXTRACT AS A GROWTH PROMOTER IN BROILER
}

\author{
D. D. Nath, M. M. Rahman, F. Akter and M. Mostofa \\ Department of Pharmacology, Faculty of Veterinary Science, Bangladesh Agricultural University, \\ Mymensingh-2202, Bangladesh.
}

\begin{abstract}
This study was conducted to determine the efficacy of tulsi (Vitex negundo) leaves, black pepper (Piper nigrum) and cloves (Curcuma longa) extract (TBC extract) as a growth promoter in broilers. A total of 20 day-old broiler chicks were purchased from Nourish Hatchery and after seven days of acclimatization the chicks were randomly divided into two equal groups A and B. No vaccination schedule was practiced and no antibiotics were added in ration of either group A or group B. Group A served as control without any supplement while group B was supplemented with TBC extract @ 1 $1 \mathrm{ml} /$ litre in drinking water. Weekly observations were recorded for live body weight gain upto $6^{\text {th }}$ weeks and blood tests were performed at $21^{\text {st }}$ and $42^{\text {nd }}$ day to find out hematological changes between control A and treatment B group. The food conversion ratio (FCR) in group A was 1.94 while that in group B was 1.87 . The result suggests that TBC extract played a vital role in gaining body weight in the treatment group B which gained significantly $(\mathrm{p}<0.01)$ higher body weight $(1660 \pm 32.80 \mathrm{gm})$ in comparison to control group A (1550 $\pm 21.20 \mathrm{gm})$. For the hematological parameters (TEC, PCV, Hb and ESR) no significant change was observed between treatment A and control B group suggesting no side effects of herbal extracts in broiler. From the findings of the present study it can be concluded that the TBC extract is economic and safe in broiler production.
\end{abstract}

Key words: Tulsi, black pepper, cloves, growth promoter, broiler

\section{INTRODUCTION}

The poultry industry has become an important economic activity in many countries including Bangladesh. Most of the poultry farmers are interested in broiler production due to its quick returns, smaller marketing age, less space requirement, and higher weight gains. Medicinal plants compete with the synthetic drugs. Majority of medicinal plants do not have the residual effects (Tipu et al., 2006). As the world is becoming more advanced, new diseases are emerging in animals and human beings by irrational use of antibiotics and antimicrobial growth promoters. Now it is the need of the time to work more extensively on the medicinal plants in the greater interest of mankind.

It is conceivable that herbal agents could serve as safer alternatives as growth promoter due to their suitability and preference, lower cost of production, reduced risks toxicity and minimum health hazards. Interestingly, recent biological trials of certain herbal formulations as growth promoter have shown encouraging results and some of the reports have demonstrated improvement with respect to weight gain, feed efficiency, lowered mortality, increased immunity and increased liveability in poultry birds (Kumar, 1991). Also these herbal growth promoters have shown to exert therapeutic effects against liver damage due to feed contaminants like aflatoxin (Ghosh, 1992). Bangladesh is abundant in herbal wealth and innumerable medicinal plants possessing interesting pharmacological properties and still awaits exploitation by scientific evidences in the field of poultry feeding. Therefore, it is a matter of great interest to try some of our indigenous medicinal plants or herbs as growth promoter in poultry diets. Various herbal products are being used as growth promoter in the poultry rations like tulsi, black pepper and cloves. Plant extracts were found to have an anti- oxidative value. Some pharmacological activities of cloves (Curcuma longa) as nematocidal and anti-inflammatory were demonstrated. Moreover, Soni et al. (1997) proved the protective effects of cloves as food additives on aflatoxin-induced mutagenicity and hepatocarcinogenicity.

*Corresponding e-mail address: mostofa57@yahoo.com

Copyright (C) 2012 Bangladesh Society for Veterinary Medicine 


\section{D. Nath and others}

Antibiotics such as avoparcin, bacitracin, lincomycin, penicillin-G-procaine, chlortetracycline and virginiamycin promote growth because of an affect on the microflora in the gastrointestinal tract (De Man, 1975). But antimicrobial resistance in zoonotic enteropathogens including Salmonella, Escherichia coli (E. coli), and Enterococci in food animals is of special concern to human health because these bacteria are likely to transfer from the food chain to humans (Endtz et al., 1991). As a consequence, the European Commission banned 4 commonly used feed antibiotics monensin sodium, salinomycin sodium, avilamycin, flavophospholipol. The banning of antibiotic growth promoter (AGP) will affect the poultry and animal industry at large. To minimize the loss in growth, there is a need to find alternatives to AGP. There are a number of nontherapeutic alternatives such as enzymes, inorganic acids, probiotics, prebiotics and herbs (Banerjee, 1998). Since ancient times, herbs and their essential oils have been known for their varying degrees of antimicrobial activity (Juven et al, 1994; Chang, 1995). More recently, medicinal plant extracts were developed and proposed for use in food as natural antimicrobials (Hsieh et al., 2001). Therefore, scientists are again concentrating on the use of our ancient medicinal system to find beneficial herbs and plants, which can be safely used to increase the production. When more than one herbs are combines it is commonly called 'polyherbal' which has attracted worldwide prominence due to its vast range of medicinal properties like antibacterial, antiviral, antifungal, antiprotozoal, hepato-protective and various other properties without showing any adverse affects (Kale et.al., 2003, Chowdhury et.al., 2009). Also, polyherbal promote growth and feed efficiency of birds because of their antibacterial and hepatoprotective properties.

However, in Bangladesh, little or no work has been done on the effects of plant extracts on body weight and performance in poultry. The present study was, therefore, conducted to determine the effect of different medicinal plant extracts (polyherbal) in broiler diets as a possible alternative to antibiotic feed additives. Considering the dangerous of indiscriminate use of antibiotics in poultry industry and the beneficial medicinal properties of indigenous herbs, this study was specifically aimed at investigating (i) the growth performance of broilers supplemented with aquous extract of tulsi, black pepper and clove (TBC extract) (ii) the effect of TBC extract on body weight gain and dressing percentage of broilers and (iii) the effects of TBC extract on the hematological parameters of broilers.

\section{MATERIALS AND METHODS}

\section{Preparation of polyherbal extract}

For the preparation of dust, the leaves of tulsi were sun-dried for 10 days and followed by oven at $55-60^{\circ} \mathrm{C}$ for 2 days. The dried tulsi leaves, black pepper and cloves were pulverized with a blender. A 25 (unit) mesh diameter sieve was used to obtain the fine dust, after that dust was preserved in airtight plastic container until they were directly used for screening and preparation of water extract. A $10 \mathrm{~g}$ tulsi leaf powder mixed with $10 \mathrm{~g}$ black peeper and $10 \mathrm{~g}$ cloves powder was added to $4 \mathrm{~L}$ distilled water, boiled until the final volume was reduced to $3 \mathrm{~L}$. Thus, the final concentration was $1 \%$.

\section{Collection and management of chicken}

Day-old broiler chicks were collected from Nourish Hatchery. The finally selected 20 chicks were allowed to acclimatize for 7 days in the experimental shed. The body weights of assigned chickens were taken with digital weight machine and the results were recorded. During acclimatization the chicken were supplied with recommended feed and water, whereas the chicks on both the extremes were discarded. During the acclimatization period the birds were fed on a commercial broiler starter mash ad libitum. After acclimatization, the chicks were randomly divided into two groups (group A and group B) having ten chicks each. Group A was kept as control without any supplement while group B was supplemented with polyherbal (TBC) extract @ $1 \mathrm{ml} / \mathrm{L}$ drinking water. The rations consisted of broiler starter mash and broiler finisher mash, which were fed from 2-4 and 5-6 weeks of age, respectively.

The experimental units were kept on a floor litter system in separate pens each measuring $3 \times 4$ square feet. The pens were thoroughly cleaned, white washed and disinfected before putting the experimental chick into these. All the birds were provided same management conditions like floor space, temperature, relative humidity, ventilation and light. The chicks were brooded at $35^{\circ} \mathrm{C}$ during first week and thereafter; the temperature was reduced by $30^{\circ} \mathrm{C}$ every week until the temperature reached to the room temperature i.e., $25 \pm 1^{\circ} \mathrm{C}$. A weighed amount of the ration was offered to the birds twice a day and the left over feed was collected to calculate feed consumption of the birds. Fresh and clean water was made available at all the times. 


\section{Experimental design}

The experiment was conducted according to the completely randomized design and data were collected on initial body weight, weekly body weight gain and weekly feed consumption. The data collected were utilized to calculate weekly growth rate, efficiency of feed utilization and mortality percentage. The data collected on the production cost of broiler were used to find out the commercial viability of the herbal growth promoter. Cost of production of the broiler in each group was calculated on per kg basis to work out the economics of production of the birds for each group. At the end of the experiment, three birds from each group were picked up randomly and slaughtered for their dressing percentage and giblet weight (heart, liver, gizzard \& spleen). The weight of pancreas was also recorded. The slaughtered birds were scalded by immuring them into the water at temperature ranging from $180-190^{\circ} \mathrm{F}$ (Jull, 1976). After that, the birds were manually plucked by hanging them on shackles by their feet. The weight of each carcass was recorded and dressing percentage was calculated on the basis of dressed meat including giblets and skin. After evisceration, the heart, liver, gizzard, spleen and pancreas of the slaughtered birds were taken out and weighed for their absolute weight. The data thus obtained were used for the calculation of (a) dressing percentage (\%) (Dress weight of bird/Live weight of bird) $\times 100)$ (b) relative weight of (i) heart (ii) liver (iii) gizzard (iv) spleen and (v) pancreas. After evisceration, relative weights (g) [(weight of organ/live body weight) X 100] of various internal organs such as liver, heart, gizzard, spleen and pancreas of the slaughtered bird were recorded. The data thus collected regarding weight gain, feed consumption, feed conversion ratio, dressing percentage and relative weights of heart, gizzard, liver, spleen and pancreas were subjected to the analysis.

\section{Hematological parameters}

Blood samples were collected from wing vein of chicken of both control and treated groups at $21^{\text {st }}$ and $42^{\text {nd }}$ day to study the effect of the TBC extract and the following parameters were observed: (a) total erythrocyte count (TEC), (b) hemoglobin estimation (Hb), (c) packed cell volume (PCV) and (d) erythrocyte sedimentation rate (ESR) by using well known methods as described by Lamberg and Rothstein (1977).

Post-mortem examination for side effects

Three chickens from each group were slaughtered to see if there were any pathological changes present on $42^{\text {nd }}$ day of treatment. There was no significant pathological change in any internal organs of the chickens of treated groups.

Statistical analysis

The data were analyzed statistically between control and treated groups of chicken by the well known student's t- test.

\section{RESULTS AND DISCUSSION}

\section{Effect of polyherbal extract supplementation on growth performance in broiler}

The mean live body weights of control and treatment groups were $1550 \pm 21.20$ and $1660 \pm 32.80 \mathrm{gm}$, respectively. It is observed from the results in Table 1 that supplementation of polyherbal extract in B group of broiler resulted significant $(\mathrm{P}<0.05)$ increase in mean live body weights as compared to control (A) group (Figure 1). Similarly, Manwar el al. (2005) supplemented pearl millet extract @ 1-2 ml/kg feed and reported significant increase in the live body weight of broiler in the fed groups when compared with control group.

Table 1. Initial and final live weight, weight gain, feed consumption and feed conversion ratio of broiler supplemented with TBC extract @ $1 \mathrm{ml} / \mathrm{L}$ of drinking water from 2 to 6 weeks of age

\begin{tabular}{|lcc|}
\hline Variables & Control (A) & Treatment (B) \\
& Mean \pm SD & Mean \pm SD \\
\hline Initial live weight $(\mathrm{g})$ on $7^{\text {th }}$ day & $110 \pm 8.77$ & $110 \pm 8.70$ \\
& $(\mathrm{n}=10)$ & $(\mathrm{n}=10)$ \\
Final live weight $(\mathrm{g})$ on $42^{\text {nd }}$ day & $1550 \pm 21.20$ & $1660 \pm 32 \cdot 80^{*}$ \\
& $(\mathrm{n}=8)$ & $(\mathrm{n}=8)$ \\
Weight gain $(\mathrm{g})$ & $1440 \pm 21.20$ & $1550 \pm 22 \cdot 02^{*}$ \\
Feed consumption $(\mathrm{g})$ & $3000 \pm 26.67$ & $3100 \pm 43.23^{*}$ \\
Feed conversion ratio & 1.94 & 1.87 \\
\hline
\end{tabular}

"Mean values within the same row, which have star marks, were significantly different $(\mathrm{P}<0.05)$. $\mathrm{A}=$ control $\mathrm{B}=1 \mathrm{ml}$ polyherbal. 


\section{D. Nath and others}

Statistical analysis of the data revealed that the supplementation of polyherbal in the broiler drinking water did exhibited significant effect on the feed intake when compared to those of the control group (Table 1). However, no difference was observed between the dressing percentages, relative gizzard weights and relative spleen weight of the birds of different feeding groups (Table 2).

Table 2. Dressing percentages, relative giblet weight (heart, gizzard, liver and spleen) and pancreas weight of broiler supplemented with TBC extract from 2 to 6 weeks of age

\begin{tabular}{|lcc|}
\hline Variables & $\begin{array}{c}\text { Control (A) } \\
(\mathrm{n}=3)\end{array}$ & $\begin{array}{c}\text { Treatment } \\
(\mathrm{n}=3)\end{array}$ \\
\hline Dressing percentage & 65.70 & 64.90 \\
Relative heart weight & 0.45 & 0.452 \\
Relative gizzard weight & 1.420 & 1.429 \\
Relative liver weight & 2.60 & 2.59 \\
Relative spleen weight & 0.11 & 0.10 \\
Relative pancreas weight & 0.27 & 0.25 \\
\hline
\end{tabular}

Table 3. Data showing economics of broiler production kept under treatment group from 2 to 6 weeks of age

\begin{tabular}{|lcc|}
\hline Description & Control (A) & Treatment (B) \\
\hline Cost/chick (Tk.) & 50.00 & 50.00 \\
Average feed consumed (Kg)/chicks & 3.000 & 3.100 \\
Feed price/kg (Tk.) & 40.00 & 40.00 \\
Cost of herbal growth promoter (Tk.) & 0.00 & 3.00 \\
Feed cost (Tk.) & 120.00 & 124.00 \\
Miscellaneous (Tk.) & 16.00 & 16.00 \\
Total cost/broiler (Tk.) & 186.00 & 194.00 \\
Average live weight (Kg) & $1.550 \pm 21.20(\mathrm{n}=8)$ & $1.660 \pm 32.80^{*}(\mathrm{n}=8)$ \\
Sale price/Kg live wt. (Tk.) & 140.00 & 140.00 \\
Sale price/broiler (Tk.) & 217.00 & 232.40 \\
Net profit/broiler (Tk.) & 31.00 & 38.40 \\
Profit/Kg live weight (Tk.) & 20.00 & 23.13 \\
\hline
\end{tabular}

Mean values within the same row, which have star marks, were significantly different $(\mathrm{P}<0.05)$.

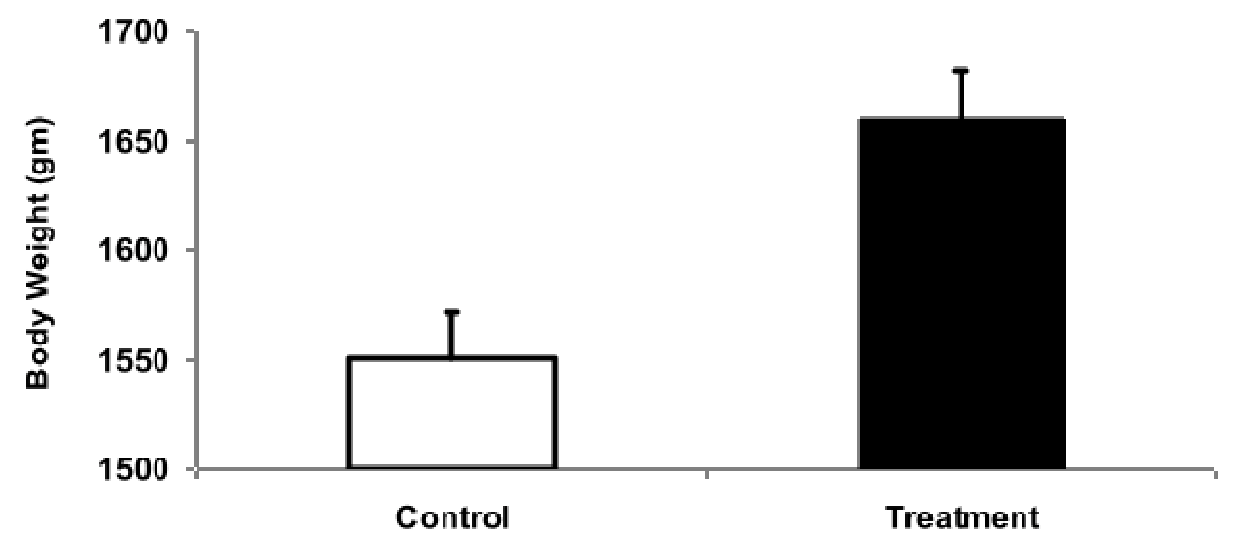

Figure 1 . Mean body weight on $42^{\text {nd }}$ day of experiment showing the significantly $(\mathrm{p}<0.05)$ higher body weight gain in the treatment group supplemented with polyherbal extract @ $1 \mathrm{ml} / \mathrm{L}$ drinking water for 2 to 6 weeks 
Dietary inclusion of TBC extract fetched the maximum profit as compared to control group. The results of the present study are in line with the findings of Ahmad (2005), who reported that dietary inclusion of polyherbal in the rations was more beneficial in broiler production. Similar results have also been reported by Ihsan (2003), who reported that broilers fed on rations with added turmeric, fetched more profit than those using rations without supplementation of this herbal growth promoter. Increase in the profit margin of the birds fed rations containing herbal growth promoter may be attributed to the better efficiency of feed utilization, which resulted in more growth and better feed conversion ratio, ultimately leading to higher profit margin in the broiler reared on polyherbal supplemented rations.

\section{Effects of polyherbal (TBC) extract on hematological parameters of broiler}

Observation of hematological parameters (RBC, Hb, PCV, ESR) on $21^{\text {st }}$ and $42^{\text {nd }}$ day did not show any significant difference $(\mathrm{P}>0.05)$ between the control and TBC extracts treated groups (Table 4).

Table 4. Effects of polyherbal (TBC) extract on hematological parameters (RBC, Hb, PCV, ESR) of broiler.

\begin{tabular}{|c|c|c|c|c|}
\hline Days & Parameters & Treatment & $\begin{array}{c}\text { Mean } \pm \text { SEM } \\
(\mathrm{n}=10)\end{array}$ & $P$ value \\
\hline \multirow{9}{*}{$21^{\text {st }}$ day } & \multirow[t]{2}{*}{$\mathrm{RBC}\left(\mathrm{mm}^{3}\right)$} & Control & $190.31 \pm 6 \cdot 39$ & \multirow[t]{2}{*}{0.144} \\
\hline & & Polyherbal & $190.87 \pm 7 \cdot 50$ & \\
\hline & \multirow[t]{3}{*}{$\mathrm{Hb}(\mathrm{gm} \%)$} & Control & $5.98 \pm 0 \cdot 10$ & \multirow[t]{3}{*}{0.11} \\
\hline & & Polyherbal & & \\
\hline & & Polyherbal & $6.50 \pm 0 \cdot 08$ & \\
\hline & \multirow[t]{2}{*}{ PCV (\%) } & Control & $17 \cdot 41 \pm 0 \cdot 75$ & \multirow[t]{2}{*}{0.419} \\
\hline & & Polyherbal & $20 \cdot 02 \pm 0 \cdot 59$ & \\
\hline & \multirow[t]{2}{*}{ ESR $\mathrm{mm}$ in $1^{\text {st }}$ hours } & Control & $11 \cdot 59 \pm 0 \cdot 79$ & \multirow[t]{2}{*}{0.126} \\
\hline & & Polyherbal & $8 \cdot 81 \pm 0 \cdot 90$ & \\
\hline \multirow{10}{*}{$\begin{array}{l}42^{\text {nd }} \\
\text { Day }\end{array}$} & \multirow[t]{2}{*}{$\mathrm{RBC}\left(\mathrm{mm}^{3}\right)$} & Control & $249.60 \pm 12 \cdot 82$ & \multirow[t]{2}{*}{0.238} \\
\hline & & Polyherbal & $277 \cdot 64 \pm 12 \cdot 10$ & \\
\hline & \multirow[t]{3}{*}{$\mathrm{Hb}(\mathrm{gm} \%)$} & Control & $7 . .03 \pm 0 \cdot 22$ & \multirow[t]{3}{*}{0.149} \\
\hline & & Polyherbal 3ml & $7.61 \pm 0 \cdot 20$ & \\
\hline & & Polyherbal & $7 \cdot 67 \pm 0 \cdot 20$ & \\
\hline & \multirow[t]{2}{*}{ PCV (\%) } & Control & $17.0980 \pm 0 \cdot 58$ & \multirow[t]{2}{*}{0.218} \\
\hline & & Polyherbal & $22 \cdot 02 \pm 0 \cdot 29$ & \\
\hline & \multirow[t]{3}{*}{ ESR $\mathrm{mm}$ in $1^{\text {st }}$ hours } & Control & $7.10 \pm 0 \cdot 58$ & \multirow[t]{3}{*}{0.236} \\
\hline & & Polyherbal 3ml & & \\
\hline & & Polyherbal & $5.320 \pm 1 \cdot 00$ & \\
\hline
\end{tabular}

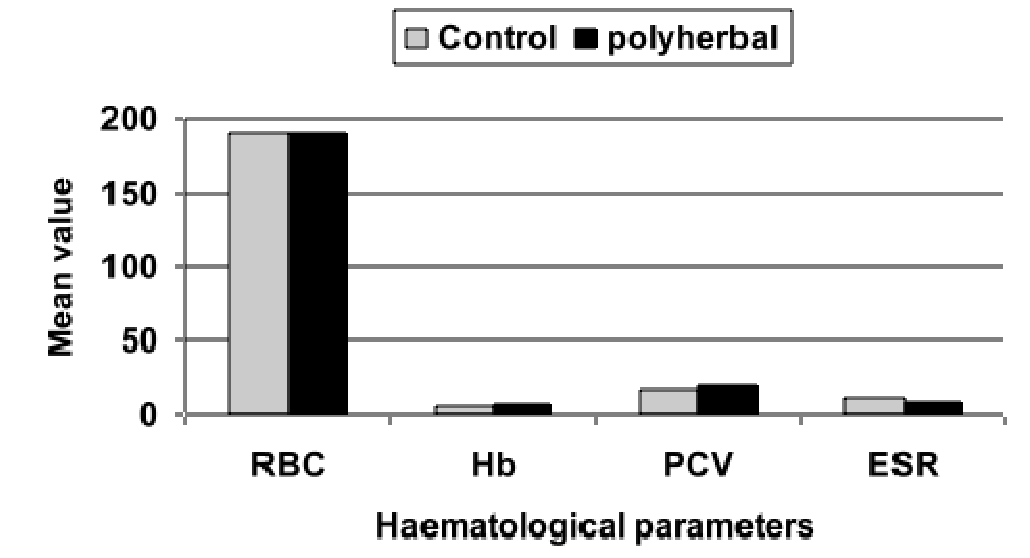

Figure 2. Haematological parameters of broiler on $21^{\text {st }}$ and $42^{\text {nd }}$ day of experiment showing no difference in the haematological parameters between control and polyherbal (TBC) treated group suggesting no harmful or side effect of polyherbal extract in broiler 


\section{D. Nath and others}

Supplementation with TBC extract in the treatment group caused improvement in the feed efficiency as compared to that of control group. Birds supplemented with TBC extract had higher body weight, weekly gain in weight, feed consumption and feed efficiency. These results may be due to antimicrobial and anti-protozoal properties (Kale et. al., 2003, Bishnu et al, 2009) of TBC, which help to reduce the microbial load of birds and thus improved the feed consumption and feed efficiency of the birds.

Our results are in line with those reported by Siddig and Abdelati (2001) who carried out a research work in broiler fed rations containing turmeric and cloves showing higher weight gain. The improvement in weight gain of the birds using cinnamon in their rations may probably be due to the fact that cinnamon extract inhibits growth of intestinal bacteria such as S. aureus and E. coli as reported by Hanafy and Hatam (1991). Resultantly, when the load of these bacteria in the intestine is low, birds may absorb more nutrients, thus leading to the improvement in weight gain of the birds using rations supplemented with turmeric and cloves. The birds fed rations supplemented with herbal growth promoter utilized their feed more efficiently than those feed ration without addition of the growth promoter. In our study, the use of polyherbal showed more increase in live weight of the birds as compared to control, which is also in agreement with the findings of Samanta and Dey (1991), who concluded that powdered cinnamon may be incorporated as a growth promoter in the ration of Japanese quails. Better feed conversion ratio of the broiler using rations supplemented with polyherbal extract may be attributed to the antibacterial properties of these supplements, which resulted in better absorption of the nutrients present in the gut and finely leading to improvement in feed conversion ratio of the rations.

This study has revealed that TBC extract had no significant effect on the haematological parameters (Table 4 and Figure 2). This finding, however, does not agree with Nagalakshmi et al. (1996) and Gowda et al. (1998) who reported that bitter principles of medicinal plants possess a strong influence on hemotological traits particularly $\mathrm{PCV}$ and $\mathrm{Hb}$ of subjects, depending on their nutritional status. This discrepancy could be explained by two ways. Firstly, the duration of the experimental period could have an influence on the haematological parameters as we know that the lifespan of $\mathrm{RBC}$ is approximately120 days. Our experiment was limited for a short period of time (42 days) in comparison to other's work. Secondly, polyherbal extracts having no significant effect on the haematological parameters in broiler may suggest that these herbs have no harmful or side effects, particularly on hematological parameters.

\section{CONCLUSION}

From the findings of the present study it can be concluded that supplementation with the tulsi, black pepper and clove extract @ $1 \mathrm{ml} / \mathrm{L}$ drinking water causes significant increase in live body weight and improvement in weekly weight gain and feed efficiency as compared to that of control group of broiler. Thus, polyherbal supplementation in the broiler rations may be useful for the safe, economical and efficient production of broiler and this formulation could be used as an alternative to commercial growth promoters.

\section{REFERENCES}

1. Ahmad S (2005). Comparative efficiency of Turmeric, garlic, Cinnamon and kalongi as growth promoter in broiler. M.Sc. (Hons.) Thesis, Department Poultry Sciences, University of Agriculture, Faisalabad, Pakistan.

2. Banerjee GC (1998). A Text Book of Animal Husbandry. 2nd edition. India publication, Delhi.

3. Bishnu J Sunil L and Anju S (2009). Antibacterial Property of Different Medicinal Plants: Ocimum sanctum, Cinnamomum Zeylanicum, Xanthoxylum armatum and Origanum majorana. Kathmandu University Journal of Science, Engineering and Technology 5: 43-50.

4. Chang HW (1995). Antibacterial effect of spices and vegetables. Food Industries 27: 53-61.

5. Chowdhury NY, Islam W and Khalequzzaman M (2009). Insecticidal activities of the leaves of nishyinda (vitex negundo verbinaceae) against tribolium castaneum hbst. Pakistan Entomologist 31: 25-31.

6. DeMan JC (1975). The probability of most probable numbers. European Journal of Applied Microbiologyand Biotechnology 1: 67-78.

7. Endtz HP, Rujis GH and Van Klingeren B (1991). Quinolon resistance in Campylobacter isolated from man and poultry following the introduction of fluroquinolones in veterinary medicine. Journal of Antimicrobial Chemotherapy 27: 199-208.

8. Ghosh TK (1992). Efficiency of liver herbal product on counteracting flatoxin on broiler birds. Indian Poultry Review 32: 33-34. 
9. Gowda SK, Verma SVS, Elangovan AV and Singh AD (1998). Neem (Azadirachta indica) kernel meal in the diet of white leghorn layer. British Poultry Science 39: 648-652.

10. Hanafy MS and Hatam ME (1991). Studies on the anti-microbial activity of $N$. sativa seed (Black cumin). Journal of Ethnopharmacology 34: 275-278.

11. Hsieh PC and Mau JL (2001). Antimicrobial effect of various combinations of plant extracts. Food Microbiology 18: 35-43.

12. Ihsan K (2003). Effect of different levels of kalongi ( $N$. sativa) seeds on the erformance of broiler M.Sc. (Hons.) Thesis, Department of Poultry Sciences, University of Agriculture, Faisalabad, Pakistan India.

13. Jull AA (1976). Poultry Husbandry. 3rd edn. Tata Mcgraw Hill Publishing Company Ltd., New Delhi, India.

14. Juven BJ, Kanner J, Schved F and Weisslowicz H (1994). Factors that interact with the antibacterial action of thyme essential oil and its active constituents. Journal of Applied Bacteriology 76: 626-631.

15. Kale B P, Kothekar M A, Tayade HP, Jaju JB and Mateenuddin M (2003). Effect of aqueous extract of Azadirachta indica leaves on hepatotoxicity induced by antitubercular drugs in rats. Indian Journal of Pharmacology 35(3), 177-180

16. Kumar OM (1991). Effect of Liv-52 syrup on broiler performance in North Eastern Region. Indian Poultry Review 22: 37-38.

17. Lamberg SL and Rothstein R (1977). Laboratory Manual of Hematology and Urinalysis. Avi. Publishing Company, Inc, West Port Connecticut, U.S.A.

18. Lin C C, Wu SJ, Chang CH and Nu LT (2003). Antioxidant activity of Cinnamomum cassia. Phytotherapy Research 17: 726-730.

19. Manwar SJ, Thirumurgan P, Konwar D, Chidanandaiah and Karna DK (2005). Effect of Azadirachta indica leaf powder supplementation on broiler performance. Indian Veterinary Journal 84: 159-162.

20. Mastura M, Nor Azah MA, Khozirah S, Mawardi R and Manaf AA (1999). Anticandidial and antidermatophic activity of Cinnamomum species essential oils. Cytobios 98: 17-23.

21. Nagalakshmi D, Sastry VRB, Agrawal RC, Ketiyar DK and Verma SVS (1996). Performance of broiler chicks fed on alkali-treated (Azadirachta indica) kernel cake as a protein supplement. British Poultry Science 37: 809-818.

22. Samanta AR and Dey A (1991). Effect of feeding garlic (A. sativum Linn.) as a growth promoter in Japanese quails (C. coturnix japonica) and its influence on dressing parameter. Indian Journal of Poultry Science 26: 42-145.

23. Siddig RM and Abdelati K (2001). Effect of dietary vitamin A and N. sativa on broiler chick's performance. In: Proc. of 10th Int. Conf. of Assoc. of Inst. for Trop. Vet. Med. Livestock. Community and Environment, Copenhegen, Denmark.

24. Soni KB, Lahiri M, Chakradeo P (1997). Protective effect of food additives on aflatoxin-induced mutagenicity and hepatocarcinogenicity. Cancer Letters 115(2): 129-13

25. Tipu MA, Akhtar MS, Anjum MI and Raja ML (2006). New dimension of medicinal plants as animal feed, Pakistan Veterinary Journal 26: 144-148. 